\title{
Survei Metrik Kompleksitas Database Relasional
}

\author{
Cahya Wulandari ${ }^{1, *}$, Shafa Risqi Oktaviary ${ }^{2}$, Yuliana Romadhoni ${ }^{3}$, Muhammad Ainul Yaqin ${ }^{4}$ \\ Jurusan Teknik Informatika, Universitas Islam Negeri Maulana Malik Ibrahim, Indonesia \\ ${ }^{1} 18650076 @$ student.uin-malang.ac.id; ${ }^{2} 18650008 @$ student.uin-malang.ac.id; ${ }^{3} 186500012 @$ student.uin- \\ malang.ac.id; ${ }^{4}$ yaqinov@ti.uin-malang.ac.id \\ * corresponding author
}

INFO ARTIKEL

Sejarah Artikel

Diterima 28 November 2019

Direvisi 6 Januari 2020

Diterbitkan 30 April 2020

\begin{abstract}
ABSTRAK
Database adalah kumpulan informasi yang disimpan di dalam komputer secara sistematik sehingga dapat diperiksa menggunakan suatu program komputer untuk memperoleh informasi dari basis data tersebut. Untuk menjaga agar sebuah database dari suatu perangkat lunak tetap terpelihara fungsinya, diperlukan sebuah metrik yang mampu mengukur tingkat kompleksitas dari database tersebut. Banyak rumus yang memberikan perhitungan kompleksitas yang sesuai untuk database tertentu. Paper ini melakukan survei terhadap jurnal-jurnal yang membahas tentang kompleksitas database. Hasil dari survei menunjukkan adanya kesamaan pada kesimpulan akhir setiap metrik meskipun parameter yang digunakan berbeda.
\end{abstract}

\section{PENDAHULUAN}

Database adalah kumpulan informasi yang disimpan di dalam komputer secara sistematik sehingga dapat diperiksa menggunakan suatu program komputer untuk memperoleh informasi dari basis data tersebut. Perangkat lunak yang digunakan untuk mengelola dan memanggil perintah (Query) basis data disebut sistem manajemen basis data (database management system, DBMS) [1]. Database juga bisa diartikan sebagai sekumpulan tabel yang saling berelasi, relasi tersebut bisa ditunjukkan dengan kunci dari setiap tabel yang ada. Satu database menunjukkan satu kumpulan data yang dipakai dalam satu perusahaan atau instansi [2]. Metrik merupakan sebuah mekanisme yang berguna untuk meningkatkan kualitas dari produk software dan juga untuk menentukan cara yang paling tepat untuk membantu praktisi dan peneliti [3][10]. Sayangnya, hampir semua metrik hanya berfokus pada karakteristik program dan mengabaikan database. Sejauh ini, beberapa penulis telah meneliti metrik untuk mengukur kompleksitas database sehingga ketahanan dan keberlangsungan database bisa terjaga. Dari penjelasan tersebut, dapat diambil kesimpulan bahwa metrik kompleksitas database merupakan sebuah mekanisme yang berguna untuk meningkatkan kualitas database sehingga ketahanan dan kualitas database dapat terjaga. Tujuan kami membandingkan metrik yang sudah ada sebelumnya adalah membantu pembaca dalam memilih menggunakan metrik yang sesuai dengan kebutuhan. Pengukuran kompleksitas database sangat diperlukan bukan hanya untuk keberlangsungan database, melainkan juga untuk keberlangsungan perangkat lunak karena jika suatu database yang dimiliki oleh perangkat lunak berkualitas baik, otomatis hal tersebut akan meningkatkan performa dari perangkat lunak itu sendiri.

\section{METODE}

\section{Systematic Literature Review (SLR)}

Terdapat beberapa artikel yang membahas kompleksitas database, jenis database yang berbeda menyebabkan masing-masingnya memiliki rumus perhitungan yang berbeda. 
Dengan menggunakan metode Systematic Literature Review (SLR), pencarian terhadap artikel terkait menjadi lebih efisien karena tidak ada duplikasi [4][12]. Pola pencarian yang kami lakukan yaitu dengan mengikuti pola:

("Metric Database Complexity" OR "Metric of Database" OR "Metric Complexity")

AND

(complexity OR metric OR measure)

AND

("Database Complexity" OR "Relational Database Complexity" OR "Relational Database Complexity Metric")

Pencarian dilakukan mulai dari tanggal 10 Februari hingga 18 Februari pada platform elektronik seperti: Google Scholar, IEEExplore, Perpusnas, ResearchGate, dan Directory of Open Access Journals. Dari hasil pencarian, didapatkan tiga paper berhubungan dengan metrik dan kompleksitas database relasional [5],[6],[7].

\section{Relational Database}

Relational database atau database relasional merupakan mekanisme yang digunakan untuk mengorganisasi data secara fisik dalam media penyimpanan yang akan berdampak pada bagaimana kita mengelompokkan dan membentuk keseluruhan data yang terkait dalam sistem yang sedang kita tinjau[8][12], pada model relasional, data akan 'disebar' ke dalam berbagai Tabel 2 dimensi. Setiap tabel selalu terdiri atas lajur mendatar yang disebut baris data(Row/Record) dan lajur menurun yang disebut kolom data(Column/Field) [9] . Relasi antar tabel ada beberapa jenis, yaitu: One to One, One to Many, Many to One, dan Many to Many. Database sendiri memiliki hirarki data yang bisa dilihat pada Gambar 1.

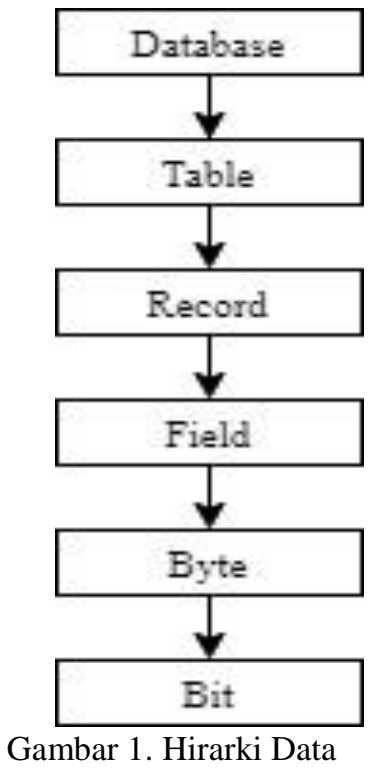

Basis data relasional memiliki beberapa elemen, antara lain: tabel, kolom(field), baris(record), key.

\section{HASIL DAN PEMBAHASAN}

Beberapa penulis dalam papernya [5],[6],[13] telah mendefinisikan rumus metrik kompleksitas database relasional. Pertama, Taufiqurrahman dkk [5], mendefinisikan rumus metrik kompleksitas database relasional sebagai berikut: 


$$
\begin{aligned}
& D C=0.75 \cdot \sum T C+0.25 \cdot \sum R C \\
& T C=0.75 \cdot \sum \mathrm{Col} C+0.25 \cdot \sum \mathrm{Key} C \\
& \text { ColC }=0.75 \cdot D T+0.25 \cdot D W \\
& \text { KeyC }=(0.28 \cdot P K+0.11 \cdot S K+0.5 \cdot F K+0.11 . \text { Index }) \\
& R C=0.25 \cdot \sum R 1: 1+0.75 \cdot \sum R 1: M
\end{aligned}
$$

Kedua, Mile dkk [6] mendefinisikan rumus metrik kompleksitas database relasional sebagai berikut:

$$
\begin{aligned}
& W=A+K+I+F \\
& C=\sum_{i=1}^{n} W i
\end{aligned}
$$

Ketiga, Bushra dan Asma [7] mendefinisikan rumus metrik kompleksitas database relasional sebagai berikut:

$$
W s=\sum_{i=1}^{6} N f * W i
$$

Setelah itu mengukur kardinalitas relationship, dan teakhir adalah mengukur kompleksitas query, form, dan reports. Tetapi kami tidak akan membahas kompleksitas query, form, dan reports, karena kami akan berfokus pada database.

Ketiga formula database diatas diuji dengan ketiga database pada Gambar 2, Gambar 3, dan Gambar 4.

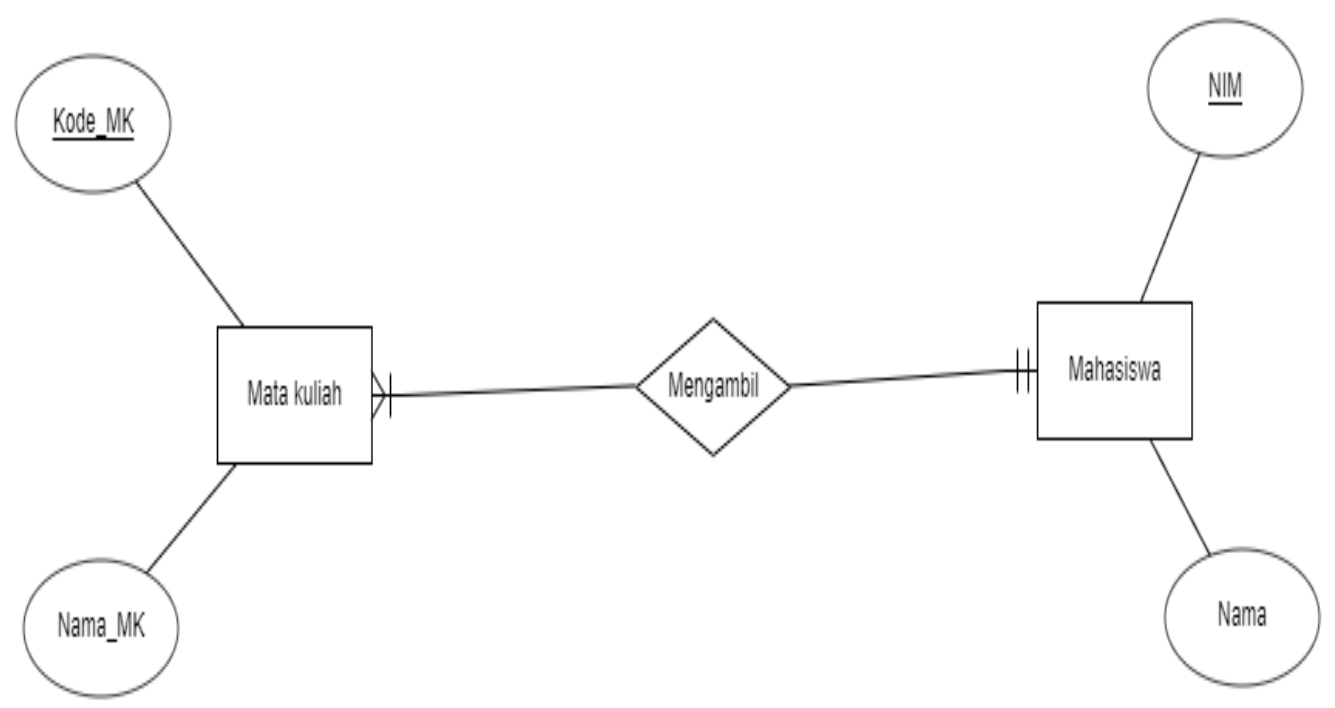

Gambar 2. Relational Database Pertama 


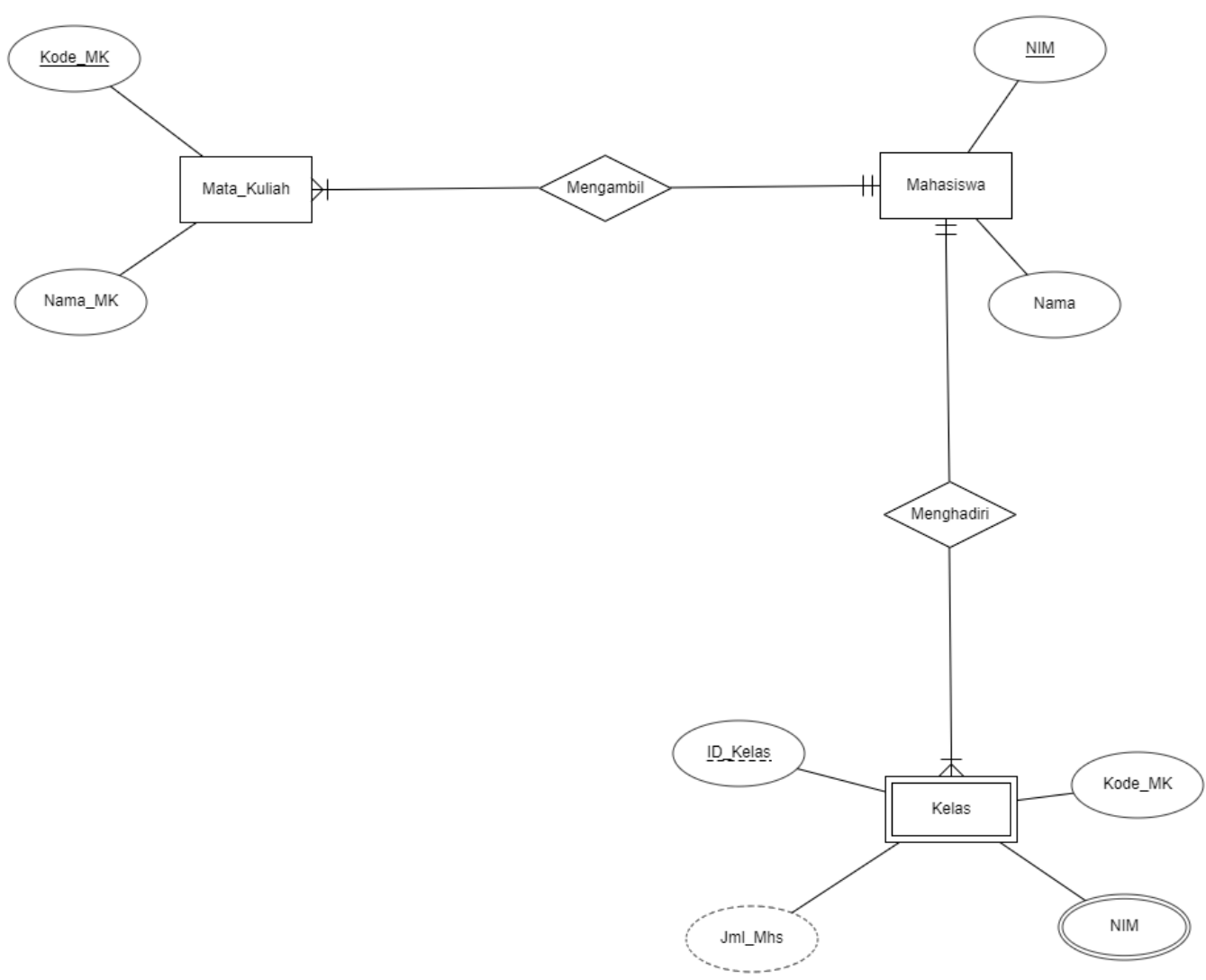

Gambar 3. Relational Database Kedua

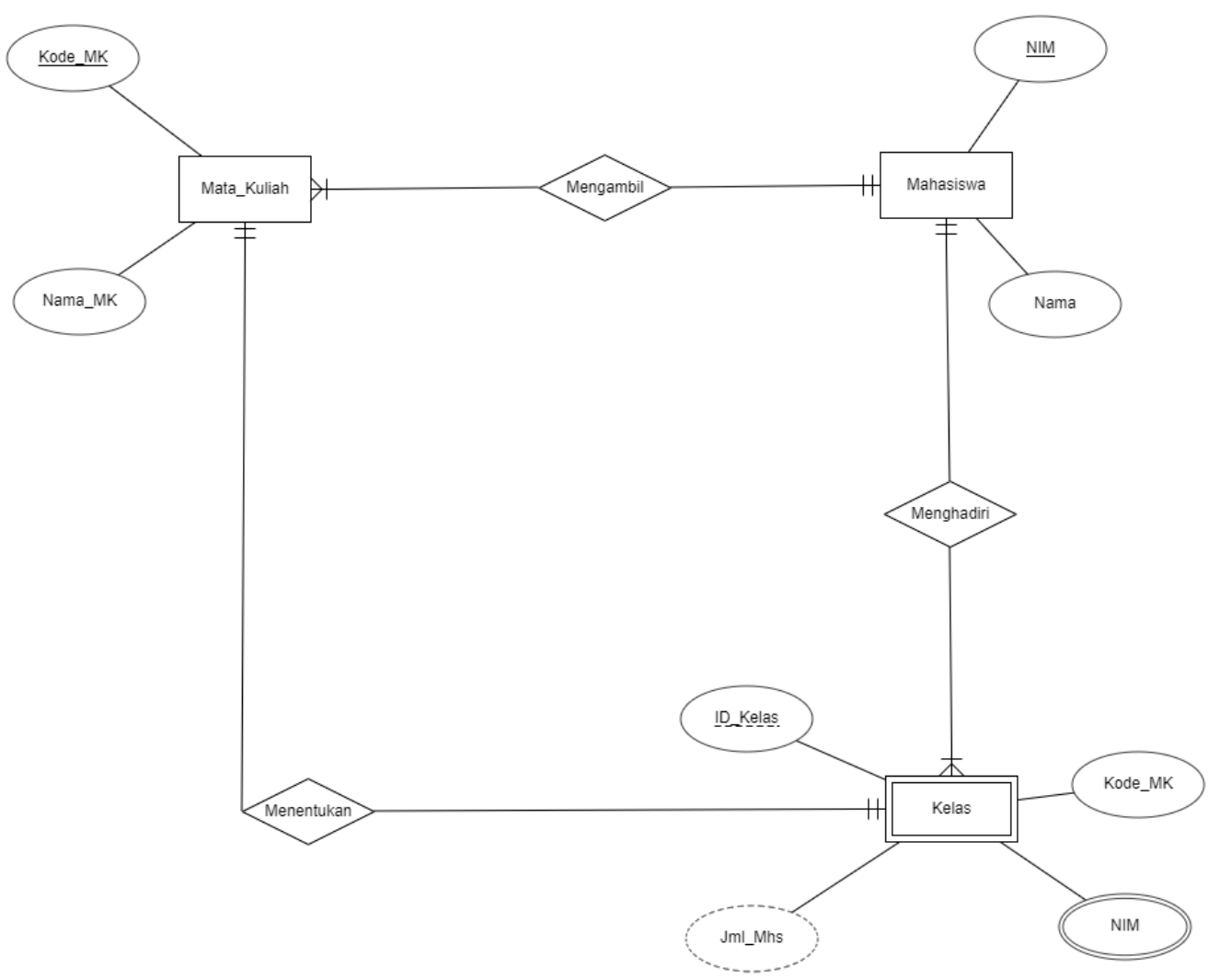

Gambar 4. Relational Database Ketiga 
Relasional database yang kami uji memiliki sifat yang berbeda-beda, sifat ketiga database diatas dijabarkan pada Tabel 1 .

Tabel 1. Sifat Database

\begin{tabular}{cccccc}
\hline Nama Database & $\begin{array}{c}\text { Jumlah } \\
\text { Tabel }\end{array}$ & $\begin{array}{c}\text { Jumlah } \\
\text { Kolom }\end{array}$ & $\begin{array}{c}\text { Jumlah } \\
\text { Relasi }\end{array}$ & Jumlah PK & Jumlah FK \\
\hline Database 1 & 2 & 4 & 1 & 2 & - \\
\hline Database 2 & 3 & 8 & 2 & 3 & 2 \\
\hline Database 3 & 3 & 8 & 3 & 3 & 2 \\
\hline
\end{tabular}

Kemudian, dari ketiga database tersebut, dilakukan ujicoba perhitungan terhadap ketiga metrik. Seperti yang terlihat pada Tabel 2, Hasil penghitungan menunjukkan bahwa ketiga metrik memiliki perbedaan yang jauh signifikan.

Tabel 2. hasil kompleksitas pada setiap metrik

\begin{tabular}{cccc} 
Metrik pada paper & Database 1 & Database 2 & Database 3 \\
\hline Taufiqurrahman dkk & 9.01 & 13.56 & 13.623 \\
\hline Mile dkk & 8 & 32 & 48 \\
\hline Bushra dan Asma & 1.5 & 2.25 & 3.5
\end{tabular}

Perbedaan kompleksitas tersebut disebabkan oleh beberapa faktor diantaranya: faktor penentu yang digunakan penulis berbeda; range kompleksitas yang digunakan setiap penulis berbeda; dan faktor penentu kompleksitas tidak memiliki nilai bobot yang sama antar penulis; contohnya, nilai kompleksitas empat pada metrik Bushara adalah complex database, tetapi nilai kompleksitas empat pada metrik Mile adalah bernilai simple database.

\section{Metrik Taufiqurrahman dkk}

Sebelum menghitung kompleksitas database, terlebih dahulu dilakukan penghitungan kompleksitas tabel, kompleksitas kolom, kompleksitas key, dan kompleksitas relasi. Berdasarkan rumus yang diajukan oleh Taufiqurrahman didapatkan hasilpada Tabel 3.

Tabel 3. Penghitungan Metrik Taufiqurrahman terhadap database

\begin{tabular}{cccccc}
\hline Nama & \multicolumn{5}{c}{ Kompleksitas Database } \\
\cline { 2 - 6 } Database & ColC & KeyC & TC & $\boldsymbol{R C}$ & DC \\
\hline Database 1 & 15.5 & 0.56 & 11.765 & 0.75 & $\mathbf{9 . 0 1}$ \\
\hline Database 2 & 23 & 1.34 & 17.585 & 1.5 & $\mathbf{1 3 . 5 6}$ \\
\hline Database 3 & 23 & 1.34 & 17.585 & 1.75 & $\mathbf{1 3 . 6 2 3}$ \\
\hline
\end{tabular}

\section{Metrik Mile dkk}

Berbeda dengan metrik yang diajukan oleh taufiqurrahman dkk, pada metrik Mile mengharuskan sebelum menentukan kompleksitas database, terlebih dahulu kita harus mencari bobot $\mathrm{W}$, dimana $\mathrm{W}=\mathrm{A}+\mathrm{K}+\mathrm{I}+\mathrm{F}$, A adalah Attribute, $\mathrm{K}$ adalah Unique Index (PK), I adalah Index (Non-Unik), dan F adalah Foreign Key. Setelah itu menghitung kompleksitasnya dengan menggunakan rumus turunan yang kedua.

Tabel 4. Penghitungan Metrik Mile terhadap database

\begin{tabular}{cccccccc}
\hline Nama & \multicolumn{7}{c}{ Kompleksitas Database } \\
Database & $\boldsymbol{A}$ & $\boldsymbol{K}$ & $\boldsymbol{I}$ & $\boldsymbol{F}$ & $\boldsymbol{W}$ & $\boldsymbol{n}$ & $\boldsymbol{C}$ \\
\hline $\begin{array}{c}\text { Database } \\
1\end{array}$ & 4 & 2 & 2 & 0 & 8 & 1 & $\mathbf{8}$ \\
\hline
\end{tabular}




\begin{tabular}{cccccccc}
\hline Nama & \multicolumn{8}{c}{ Kompleksitas Database } \\
\cline { 2 - 8 } Database & $\boldsymbol{A}$ & $\boldsymbol{K}$ & $\boldsymbol{I}$ & $\boldsymbol{F}$ & $\boldsymbol{W}$ & $\boldsymbol{n}$ & $\boldsymbol{C}$ \\
\hline $\begin{array}{c}\text { Database } \\
2\end{array}$ & 8 & 3 & 3 & 2 & 16 & 2 & $\mathbf{3 2}$ \\
\hline $\begin{array}{c}\text { Database } \\
3\end{array}$ & 8 & 3 & 3 & 2 & 16 & 3 & $\mathbf{4 8}$ \\
\hline
\end{tabular}

\section{Metrik Bushra dan Asma}

Penulis memiliki aturan sendiri dalam menghitung komplektitas database, hal ini perlu diperhatikan sebelum mulai menghitung kompleksitas database. Bushra dan Asma memiliki aturan dalam penilaian bobot kompleksitas sebelum menghitung kompleksitas database. Pertama adalah aturan bobot untuk kompleksitas tabel. Aturan bobot tersebut mencakup nilai bobot untuk setiap faktor penentu kompleksitas tabel (CDF, eng: Complexity Determining Factor). bisa dilihat pada Tabel 5.

Tabel 5. CDF Kompleksitas Tabel Metrik Bushara dan Asma

\begin{tabular}{cc} 
CDF untuk table & Bobot \\
\hline Simple data type field & 0.25 \\
\hline Complex data type & 0.50 \\
\hline Each Field in Primary Key & 0.25 \\
\hline Each Field in Foreign Key & 0.50 \\
\hline Assertion & 0.75 \\
\hline Trigger & 075 \\
\hline
\end{tabular}

Kedua adalah aturan bobot untuk relasi antar tabel pada Tabel 6:

Tabel 6. CDF Kompleksitas Relasi Metrik Bushara dan Asma

\begin{tabular}{ccc}
\hline CDF untuk Relasi & $\begin{array}{c}\text { Bobot } \\
\text { Unary }\end{array}$ & $\begin{array}{c}\text { Bobot } \\
\text { Binary }\end{array}$ \\
\hline One-to-one & 0.25 & 0.25 \\
\hline One-to-Many & 0.50 & 0.50 \\
\hline One-to-Many (RI Enforced) & 0.75 & 0.75 \\
\hline Many-to-Many & 0.75 & 0.75 \\
\hline
\end{tabular}

Selanjutnya, untuk menggabungkan nilai kompleksitas tabel dan kompleksitas relasi tersebut menggunakan rumus:

$$
C=\sum C D F T+\sum C D F R
$$

Hasil kompleksitas database yang kami ajukan untuk metrik Bushra dan Asma terdapat pada Tabel 9. CDF Tabel:

Tabel 7. CDF Tabel masing-masing database

\begin{tabular}{ccccc}
\hline CDF untuk tabel & Bobot & Databse 1 & Database 2 & Database 3 \\
\hline Simple data type field & 0.25 & 2 & 2 & 2 \\
\hline Complex data type & 0.50 & 0 & 0 & 0 \\
\hline Each Field in Primary Key & 0.25 & 2 & 3 & 3 \\
\hline Each Field in Foreign Key & 0.50 & 0 & 2 & 2 \\
\hline Assertion & 0.75 & 0 & 0 & 0 \\
\hline Trigger & 075 & 0 & 0 & 0 \\
\hline
\end{tabular}


CDF untuk tabel

Bobot

Databse 1 Database 2 Database 3

TOTAL 1

2.25 2.25

CDF Relasi:

Tabel 8. CDF Relasi masing-masing database

\begin{tabular}{cccccc}
\hline CDF untuk Relasi & Bobot & Bobot & Database & Database & Database \\
Unary & Binary & $\mathbf{1}$ & $\mathbf{2}$ & $\mathbf{3}$ \\
\hline One-to-one & 0.25 & 0.25 & 0 & 0 & 1 \\
\hline One-to-Many & 0.50 & 0.50 & 1 & 2 & 2 \\
\hline One-to-Many (RI Enforced) & 0.75 & 0.75 & 0 & 0 & 0 \\
\hline Many-to-Many & 0.75 & 0.75 & 0 & 0 & 0 \\
\hline TOTAL & & & $\mathbf{0 . 5}$ & $\mathbf{1}$ & $\mathbf{1 . 2 5}$ \\
\hline
\end{tabular}

Kompleksitas Database:

Tabel 9. hasil kompleksitas database menggunakan metrik Bushara dan Asma

Faktor Penentu

Database 1 Database 2 Database 3

\begin{tabular}{cccc}
\hline CDF Tabel & 1 & 2.25 & 2.25 \\
\hline CDF Relasi & 0.5 & 1 & 1.25 \\
\hline Nilai Kompleksitas & $\mathbf{1 . 5}$ & $\mathbf{2 . 2 5}$ & $\mathbf{3 . 5}$ \\
\hline
\end{tabular}

Nilai kompleksitas ketiga metrik berbeda karena rumus yang diajukan pun berbeda. Akan tetapi, terdapat persamaan yang terlihat jelas. Persamaan tersebut adalah nilai kompleksitas database pertama akan selalu lebih kecil dibandingkan dengan nilai kompleksitas database kedua, dan nilai kompleksitas database kedua akan selalu lebih kecil dibanding nilai kompleksitas database ketiga, lihat tabel 2. Artinya, tujuan yang setiap penulis miliki pada metrik yang mereka teliti sudah terpenuhi.

\section{KESIMPULAN}

Paper ini telah melakukan survey terhadap ketiga metrik database relasional, setelah melakukan uji coba terhadap metrik-metrik tersebut didapatkan hasil yang berbeda-beda. Hal ini disebabkan oleh beberapa faktor, yaitu: faktor penentu yang digunakan penulis berbeda; range kompleksitas yang digunakan setiap penulis berbeda; dan faktor penentu kompleksitas tidak memiliki nilai bobot yang sama antar penulis; akan tetapi, nilai akhir dari kompleksitas menunjukkan kesamaan dimana kompleksitas database pertama lebih kecil dari kompleksitas database kedua dan kompleksitas database kedua lebih kecil dari kompleksitas database ketiga. hal ini menunjukkan bahwa setiap metrik yang ditawarkan oleh penulis telah memenuhi tujuan mereka. Kami menyarankan untuk menggunakan metrik yang sesuai dengan kebutuhan database yang kita miliki.

\section{REFERENSI}

[1] Ullman, Jeffrey D. A first course in database systems. Pearson Education India, 2007.

[2] Fadlisyah, Asrianda. "Pemrograman database konsep dan implementasi". Graha Ilmu, Yogyakarta, 2008.

[3] Calero, Coral; Piattini, Mario; Genero Marcela. "Metrics for controlling database complexity". In: Developing quality complex database systems: practices, techniques and technologies. IGI Global, pp. 48-68, 2001.

[4] Polancic, Gregor; Cegnar, Blaž. "Complexity metrics for process models-A systematic literature review”. Computer Standards \& Interfaces, vol. 51, pp. 104-117, 2017.

[5] Idrus, Taufiqurrahman, et al. "Metrik Kompleksitas Desain Database Relasional”. In: Prosiding SI 
MaNIs (Seminar Nasional Integrasi Matematika dan Nilai-Nilai Islami), pp. 090-096, 2020.

[6] Pavlic, Mile; Kaluza, Marin; Vrcek, Neven. "Database complexity measuring method". In: Central European Conference on Information and Intelligent Systems. Faculty of Organization and Informatics Varazdin, pp. 1, 2008.

[7] Jamil, Bushra; Batool, Asma. "Smarts: Software metric analyzer for relational database systems". In: 2010 International Conference on Information and Emerging Technologies. IEEE, pp. 1-6, 2010.

[8] Rabbi, Radliya Nizar. Materi 3-Basis Data Relasional [sbd-2017]. 2017.

[9] Suryana, Taryana. bab 14. Database Relasional. 2004.

[10] M. A. Yaqin, R. Sarno, and A. C. Fauzan, "Scalability measurement of business process model using business processes similarity and complexity," Int. Conf. Electr. Eng. Comput. Sci. Informatics, vol. 4, no. September, pp. 306-312, 2017.

[11] A. C. Fauzan, R. Sarno, and M. A. Yaqin, "Performance measurement based on coloured petri net simulation of scalable business processes," Int. Conf. Electr. Eng. Comput. Sci. Informatics, vol. 4, no. September, pp. 261-266, 2017.

[12] A. C. Fauzan, R. Sarno, M. A. Yaqin, and A. Jamal, "Extracting common fragment based on behavioral similarity using transition adjacency relations for scalable business processes," Proc. 11th Int. Conf. Inf. Commun. Technol. Syst. ICTS 2017, vol. 2018-Janua, pp. 131-136, 2018.

[13] A. C. Fauzan, R. Sarno, and M. A. Yaqin, "Petri net arithmetic models for scalable business processes," Proceeding - 2017 3rd Int. Conf. Sci. Inf. Technol. Theory Appl. IT Educ. Ind. Soc. Big Data Era, ICSITech 2017, vol. 2018-Janua, pp. 104-109, 2017. 